\title{
Perioperative Complications and Long-Term Outcome of Salvage Radical Prostatectomy Compared to Primary Radical Prostatectomy
}

\author{
Annabel Spek*, Alexander Buchner, Bernadett Szabados, Christian Gratzke, Alexander Karl and Christian G \\ Stief
}

Department of Urology, University Hospital of Munich, Germany

Submission: January 03, 2017; Published: January 30, 2017

*Corresponding author: Annabel Spek, Department of Urology, University Hospital of Munich, Germany, Tel: 0049/89 4400 0; Fax: 0049/89 4400 75444; Email: Annabel.spek@med.uni-muenchen.de

\begin{abstract}
Objective: To assess whether salvage radical prostatectomy ( $\mathrm{rPx}$ ) after external beam radiotherapy (EBRT), brachytherapy (BT) or high intensity focused ultrasound (HIFU) is a valuable therapeutic option and efficacious in tumor control.

Material and methods: 36 patients with local recurrence of prostate cancer (PC) after primary curative EBRT, BT or HIFU underwent open salvage rPx. Preoperative imaging was done by choline PET or PSMA PET-CT to check for a possible systemic disease as cause of biochemical recurrence (BCR) in all patients. We evaluated peri and post-operative complications and compared these to open rPx as primary treatment of PC as well as we did for functional and oncologic outcomes. BCR after salvage rPx was defined as a PSA-increase above $\geq 0.2 \mathrm{ng} / \mathrm{ml}$.
\end{abstract}

Results: Primary treatment was EBRT in 21 patients (58\%), BT in 7 (19\%), a combination of both in 1 (3\%) and HIFU in 7 pts (19\%). Median age was 69 years (range 58-78) and median preoperative PSA was $5.7 \mathrm{ng} / \mathrm{ml}$ (range 0-197). No major intra- or postoperative complications were observed. Median intra-operative blood loss was $200 \mathrm{ml}$ (50-1000), no transfusion was needed and median operating time was 75 min (46-169 $\mathrm{min}$ ) - comparable to the data of primary treatment with open $\mathrm{rPx}$ of 4,837 pts from 2004-2015 with no statistically significant difference. Median follow-up (FU) was $48 \mathrm{~m}$ (range 3-131). Patho-histological tumor stage was ypT3 in 58\% (21/36), ypT2 in 28\% (10/36) and other (урт0, урTх) in 14\% (5/36). Positive lymph nodes were found in 33\% (12/36), distant metastases in 6\% (2/36).

Follow-up data were available from 34/36 patients. 35\% (12/34) had to undergo resection of the anastomosis because of a postsurgical stricture. After 12 and 36 months post-surgery, $33 \%$ and $50 \%$ needed $\geq 3$ pads per day in contrast to $6 \%$ and $5 \%$ in the control group. $84 \%$ and $85 \%$ of patients treated with salvage rPx had an IIEF-Score of 0 - compared to $33 \%$ and $36 \%$, respectively. Median disease-free interval was 42 months; 56\% (19/34) showed BCR during the FU-interval. Eight patients died of PC during the FU.

Conclusion: Salvage rPx after EBRT, BT or HIFU is a feasible and valuable option for a well-informed individual patient and can lead to a significant BCR-free survival. However, the patient must be well informed about the burden of a salvage procedure. Regarding the poor results of cancer control, we have to realize that failure after EBRT and BT is obviously detected too late and is associated with a mostly poor differentiated prostate cancer. As a consequence, we should consider to escalate the follow up diagnostic after radiotherapy, e.g. multi-parametric magnetic resonance imaging (mpMRI) or biopsy after 12 months in cases of an insufficient PSA level.

Keywords: Prostatectomy; Salvage therapy; Rising PSA; Radiation therapy; External beam radiotherapy; Brachytherapy; Prostate specific antigen; Androgen deprivation therapy

Abbreviations: EBRT: External Beam Radiotherapy; BT: Brachytherapy; HIFU: High Intensity Focused Ultrasound; PC: Prostate Cancer; BCR: Biochemical Recurrence; mpMRI: Multi-Parametric Magnetic Resonance Imaging; PSA: Prostate Specific Antigen; rPX: Radical Prostatectomy; PET: Positron Emission Tomography; IIEF: International Index Of Erectile Function; ADT: Androgen Deprivation

\section{Introduction}

Prostate cancer is the most common malignancy in men and the third most common cause of cancer related death $[1,2]$. Recurrence of prostate cancer after curative attempted treatment ranges from 20-40\% [3-5]. Monitoring serum prostate specific antigen (PSA) after treatment of localized prostate cancer (PC) was routinely done to detect early disease 
recurrence. It leads to the identification of men with a PSA-only (biochemical) recurrence after definitive treatment for localized disease, usually without the appearance of signs or symptoms of either loco regional recurrence or distant metastasis disease. Following primary treatment with radiation therapy, 30\% of patients developed a disease recurrence with a rising serum PSA [6]. 72\% of these patients with recurrence after external radiation therapy will have locally recurrent disease [5].

Locally recurrence with an increasing PSA is a significant risk factor for subsequent metastatic progression and cancer specific mortality $[3,5,7]$. Patients with isolated local recurrence after radiation therapy have several options for treatment including surgery, androgen deprivation therapy (ADT), brachy therapy or cryotherapy [8]. Therefore, a significant number of these patients may benefit from a salvage therapy. However, the data of CaPSURE database showed that only $2 \%$ of these patients were subsequently treated with salvage radical prostatectomy (rPx) [9].

For selected patients with clinical characteristics of localized relapse, salvage $\mathrm{rPx}$ has been shown to provide a good biochemical recurrence-free and metastasis-free survival rate at 5 years after salvage $\mathrm{rPx}$ [10]. A recent comparison revealed superior overall survival for patients treated with $\mathrm{rPx}$, longterm data are limited regarding the use of cryotherapy in the salvage setting [11]. Salvage surgery of the prostate is a rare treatment for management with recurrent disease; this can be attributed in part of the technical challenge of the procedure [12] and in association with an increased risk of significant complications [13] with high oncologic failure: early perioperative complications ranged from $13 \%$ to $27 \%[14,15]$, higher rates of urinary incontinence and anastomotic stricture were described than those observed after radical prostatectomy as initial therapy $[8,13,14]$. Erectile dysfunction is generally a consequence of salvage $\mathrm{rPx}$.

In our present study we provide an analysis of peri- and postoperative as well as the functional and oncological outcomes of open salvage rPx cases undertaken at our institution. This analysis is to assess whether salvage radical prostatectomy after failed external beam radiotherapy (EBRT), brachytherapy (BT) or high intensity focused ultrasound (HIFU) is efficacious in terms of tumor control.

\section{Material and Methods}

Between April 2004 and April 2015, 4,873 subsequent patients underwent open radical retropubic prostatectomy at the University Hospital of Munich. Out of these, we identified 36 patients who underwent salvage $\mathrm{rPx}$ after previous failed treatment of localized prostate cancer. All of them gave their written informed consent; all were included in our study and follow dafter salvage therapy. All patients had BCR of $2 \mathrm{ng} / \mathrm{ml}$ above the nadir after radiation - based on the Phoenix criteria [16]. To exclude patients with systemic disease as cause of increasing PSA, preoperative imaging was done by 11C-choline Positron Emission Tomography (PET) or PSMA PET-CT. The selection criteria for salvage rPx included patients with suspected significant locally recurrence and absence of systemic disease with a life expectancy of more than 10 years. One exception was a patient who presented bone lesions in preoperative imaging and the surgery was done by his express request. These patients were included, data evaluated and followed by a 3 months interval.

Clinical information regarding patient characteristics, age, primary treatment of the prostate cancer, and preoperative serum PSA as well as histopathological report were collected. We evaluated peri-operative data, operating time, intraoperative blood loss and the Gleason-score of the prostate after salvage treatment. Postoperative data and complications were collected. Peri- and postoperative data and complication rate was compared to data of primary radical prostatectomy. For comparison of the functional results, data of 4,837consecutive patients undergoing primary $\mathrm{rPx}$ were collected and could be correlated to the data of salvage rPx. Follow-up was performed with a clinical examination including digital rectal examination, transurethral sonography and serum PSA.

Primary end points analyzed in this study were progressionfree (PFS) and overall survival (OS) following salvage $\mathrm{rPx}$. Disease progression was defined by PSA $>0.2 \mathrm{ng} / \mathrm{ml}$ followed by two confirmative rises or radiologic/histological evidence of systemic disease. Functional outcome regarding continence and potency status was evaluated using the International Index of Erectile Function (IIEF) [17] and the number of needed pads per day. Long-term postoperative complications regarding transurethral resection of the anastomosis because of a stricture were reported likewise.

\section{Statistical analysis:}

PFS was calculated as interval between the date of salvage $\mathrm{rPx}$ and the data of first documented progression by serum PSA $>0.2 \mathrm{ng} / \mathrm{ml}$ or initiation of androgen deprivation therapy (ADT). Kaplan-Meier analysis was used to estimate the probabilities of PFS and OS. For comparison of continuous variables between several groups Kruskal-Wallis ANOVA was used. $\mathrm{P}<0.05$ was regarded as significant. All calculations were performed using the software STATISTICA 10 (Stat Soft, Tulsa, OK) and MedCalc 15 (MedCalc, Ostend, Belgium).

\section{Results}

All patients received primary treatment with curative intent in the form of EBRT $\left(\mathrm{n}^{0} 21\right), \mathrm{BT}\left(\mathrm{n}^{0} 7\right)$, a combination of both $\left(\mathrm{n}^{0} 1\right)$ and HIFU ( $\left.n^{0} 7\right)$ between 1998 and 2013. Median time interval between primary therapy and salvage rPx was 47 months (range 13-157 months). Median patient age at time of salvage rPx was 69 years (range 58-78 years). Preoperative serum PSA ranged from 0 to $197 \mathrm{ng} / \mathrm{ml}$ with a median of $5.7 \mathrm{ng} / \mathrm{ml}$. All patients 
with a preoperative PSA level below $2 \mathrm{ng} / \mathrm{ml}$ had androgen deprivation therapy induced by their referring urologist before surgery. There was no significant difference regarding preoperative PSA level, age and time to salvage $\mathrm{rPx}$ in relation to the first treatment (EBRT, BT, HIFU).

Peri-operatively, no major complications were observed such as blood transfusion, rectal injury or revision surgery. Median intra-operative blood loss intra-operative was $200 \mathrm{ml}$ with a range of $50 \mathrm{ml}$ to $1000 \mathrm{ml}$. Median operative time was $75 \mathrm{~min}$ (range 46 to $169 \mathrm{~min}$ ). There were no significant differences between the types of prior treatment and surgical outcome (Table 1). No major 30 days and 90 days post-operative complications were reported. One patient got a stricture of his anastomosis within 90 days post-operative.

Table 1: Prior treatment.

\begin{tabular}{|c|c|c|}
\hline & $\mathbf{n}$ & $\%$ \\
\hline EBRT & $21 / 36$ & 58 \\
\hline BT & Jul-36 & 19 \\
\hline BT+EBRT & Jan-36 & 3 \\
\hline HIFU & Jul-36 & 19 \\
\hline
\end{tabular}

\section{Pathologic findings}

Poorly differentiated cancer with a Gleason 8 or higher was identified in $44 \%(16 / 36)$ of the surgical specimens. $8 \%$ (3/36) had a Gleason 6, 19\% (7/36) Gleason 7a, 14\% (5/36) a Gleason $7 \mathrm{~b}$ and in $14 \%(5 / 36)$ there could not be found any vital tumor tissue within the removed prostate (Table 2). Lymph node involvement was present in 33\% (12/36) of the cohort, and distant metastases were present in $3 \%(1 / 36)$ of the patients; another patient developed distant metastases 8 months after salvage $\mathrm{rPx}$. Among the patients with vital tumor, $48 \%$ (15/31) demonstrated a positive surgical margin (Table 3). Corresponding to the TNM Classification UICC 2010 [18], 28\% (10/36) had an ypT2 tumor, 58\% (21/36) demonstrated an ypT3 distension and other classification such as T0 or TX was found in $14 \%$ (5/36). 10\% (1/10) of the patients with ypT2 tumor had positive margin status and $67 \%(14 / 21)$ of the patients with ypT3 tumor, respectively.

Table 2: Gleason of the tumor tissue of salvage rPx, radiation before.

\begin{tabular}{|c|c|c|}
\hline & $\mathbf{n}$ & $\%$ \\
\hline Gleason 6 & $3 / 36$ & 8 \\
\hline Gleason 7a & $7 / 36$ & 19 \\
\hline Gleason 7b & $5 / 36$ & 14 \\
\hline Gleason 8-10 & $16 / 36$ & 44 \\
\hline $\begin{array}{c}\text { no vital } \\
\text { tumourtissue }\end{array}$ & $5 / 36$ & 14 \\
\hline
\end{tabular}

Table 3: Continence rates 12 and 36 months after salvage rPx.

\begin{tabular}{|c|c|c|}
\hline Pads Per Day & $\begin{array}{c}\text { 12 Months } \\
\text { Postsurgery }\end{array}$ & $\begin{array}{c}\text { 3 years } \\
\text { Postsurgery }\end{array}$ \\
\hline 0 & $\mathrm{n}=15$ & $\mathrm{n}=14$ \\
\hline 1 & $53 \%(8 / 15)$ & $35 \%(5 / 14)$ \\
\hline 2 & $13 \%(2 / 15)$ & $7 \%(1 / 14)$ \\
\hline 3 ormore & $0 \%(0 / 15)$ & $7 \%(1 / 14)$ \\
\hline
\end{tabular}

\section{Oncologic outcome}

The median follow-up time of the cohort after salvage $\mathrm{rPx}$ was 48 months (range 3-131 months). Data of survival and recurrence rates was available from 34 of 36 included patients (94\%). 29\% (10/34) of these patients were treated with ADT. $56 \%$ (19/34) of the patients developed a biochemical recurrence after salvage $\mathrm{rPx}$. The median biochemical recurrence-free time was 43 months (Figure 1). 24\% (8/34) of the patients died during the follow up, seven as a result of PC and one because of non-cancer related cause. The median overall survival was not reached during follow-up (Figure 2). The median serum PSA preoperative was $6.2 \mathrm{ng} / \mathrm{ml}$. Patients with PSA level up to $6.2 \mathrm{ng} / \mathrm{ml}$ had a significant longer BCR-free survival (64 months) compared to patients with high preoperative PSA above the median of $6.2 \mathrm{ng} / \mathrm{ml}$ ( 24 months; $\mathrm{p}=0.021$ ). Regarding overall survival, the difference is important, but does not reach statistical significance $(\mathrm{p}=0.106)$.

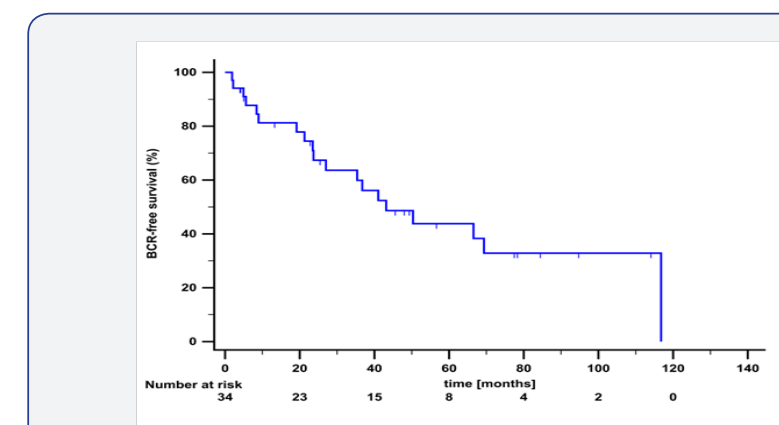

Figure1: BCR-Free survival.

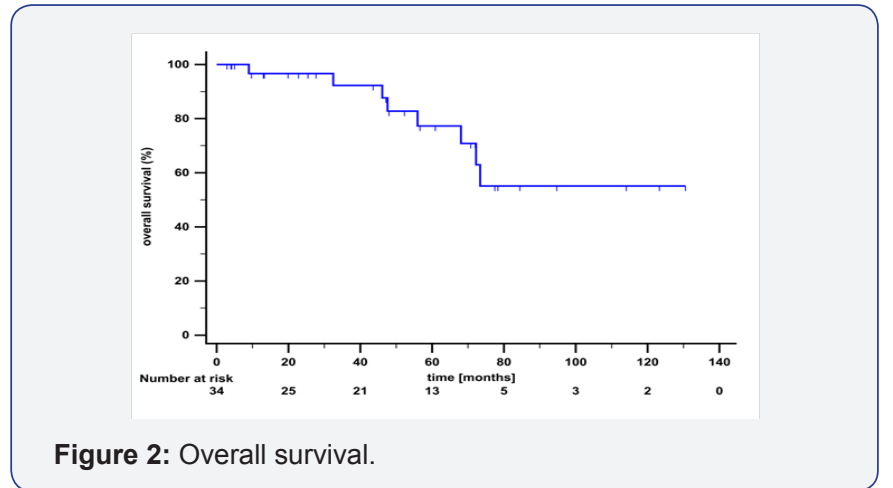




\section{Functional outcome}

Continence and potency rates were reported by standard IEFF and needed pads per day. With increasing follow up time, data of functional outcome was available from a decreasing number of cases because of the patients deceasing during follow-up.

Anastomosis stricture rate was 35\% (12/34). 50\% of the patients with a stricture developed more than one stricture that has been handled surgically. As for continence rates, 53\% of the patients after one year and $36 \%$ after 3 years were continent and did not need any pad. The corresponding proportions in the patients treated with primary $\mathrm{rPx}$ were $6 \%$ and $5 \%$. After one year and after 3 years, $13 \%$ and $7 \%$ of the salvage rPx patients needed one pad per day, respectively. $33 \%$ and $50 \%$ of the patients with salvage rPx needed 3 or more pads per day one and 3 years after surgery, respectively. The decreasing rate of continence over the years can be explained because of the high anastomotic stricture rate and the surgical treatment of it. More than $50 \%$ needed more than one resection of the stricture and this is a relevantly high factor for incontinence.

Potency following salvage $\mathrm{rPx}$ was evaluated using the IIEF score scaled from 0 , severe dysfunction to 30 , no erectile dysfunction, categorized in 5 classifications. 12 months after salvage $\mathrm{rPx}, 84 \%$ of the patients had a severe dysfunction (IIEF score 6-10), the other $16 \%$ had a moderate to mild dysfunction (IIEF score 11-25). After 36 months $85 \%$ of the patients had IIEF score $<10$ equivalent to severe dysfunction, $15 \%$ had IIEF score 11-21. In comparison, the proportions of IIEF score 6-10 severe erectile dysfunction in the patients with primary rPx was 33\% after one year and $36 \%$ after three years in the unselected group of all $\mathrm{rPx}$, respectively.

\section{Discussion}

Local salvage therapy is a rare treatment option for patients with localized cancer recurrence who failed primary curative therapy of the prostate cancer. The patterns of care for salvage therapy after failed radiation therapy were shown in the CaPSURE database [3] and in the study from Tran, et al. [19]: Most of the patients with BCR received ADT. Only a small number of patients got a local salvage therapy such as salvage $\mathrm{rPx}$, salvage EBRT, salvage HIFU or salvage cryotherapy with or without ADT. Therefore, there are only a few studies with mostly small cohorts evaluating data of salvage therapies. Prostate cancer is a common disease; patients getting younger at time of diagnosis and became older today compared to the generation before. All of them aspired to have a good and healthy life quality in higher ages. Thus, salvage management with reliable oncological and good functional outcome will be more important.

The peri-operative morbidity associated with salvage rPx was very low compared to other series that report rectal injuries, blood transfusions and technical complications in 29\%, 50-60\% and $15 \%[14,20-23]$. Urinary incontinence was reported to persist in 50\%. In our department and in a recent series [14], the implantation of an incontinence sling or an artificial sphincter would be offered in these cases. In general, urinary continence after salvage $\mathrm{rPx}$ is poor, but our series as well as other studies demonstrate an improvement over time [20,24].

Erectile function after salvage surgery was very poor. Other studies showed similar results of potency rates with better outcome for those men who had a good erectile function prior to salvage rPx. [25,26] Heidenreich, et al. [24] demonstrated a profound difference in recovery of urinary continence depending on type of prior RT. This cannot be derived from our data. To our knowledge, the salvage surgery is technical difficult because of the extent of fibrosis and scarring tissue following radiation therapy. In most cases, the surgical technique had to be modified because of dense peri-prostatic fibrosis and close adherence to the anterior surface of the rectum, thus an inter- or intra-facial nerve-sparing $\mathrm{rPx}$ seems unrealistic.

About 26\% of patients following EBRT for stage T1-2 PC with increased serum PSA or did not reach PSA nadir harbor localized persistent cancer and did not develop systemic disease [27]. This is a significant risk factor for subsequent metastatic disease and local morbidity if left untreated [28,29]. Salvage $\mathrm{rPx}$ is a reliable treatment option that has provided long-term cancer control and therefore, should be considered more often in the management of locally radio recurrent PC $[14,15,20,30]$

Bianco, et al. [14] published in 2005 long-term oncologic results from the Memorial Sloan Kettering Cancer Center (MSKCC). On this multivariable analysis, the preoperative serumPSA level was the only preoperative factor that showed to be a significant predictor of disease progression. In 1998, Cheng, et al. [31] found the same in his cohort. In our study, we had a similar trend with a worse outcome for patients above the median PSA of 6.2. These results with a poor outcome when a high PSA is present after primary therapy suggest that failure after EBRT, BT or HiFu must be detected early to save the individual's life.

At present, the Phoenix-criteria [16] define PSA failure after RT:A PSA rise of $2 \mathrm{ng} / \mathrm{ml}$ or more above the PSA nadir is considered the standard definition for biochemical recurrence after external beam RT, with or without androgen deprivation therapy. Given the poor oncological outcome of salvage $r P x$ in various series including ours presented here, other and/or additional parameters are needed to define treatment failure after radiotherapy. In our series, the median time of primary therapy to salvage surgery was 47 months. This interval of roughly 4 years is comparable to other series and obviously, this interval is too long for an early detection of recurrent cancer after radiation therapy [24,32]. Given these results, monitoring after radiation therapy for prostate cancer must be refined other than measuring PSA. Here, modern imaging as multi-parametric MRI or prostate biopsy should be applied early in case of an insufficient drop in PSA. 


\section{Conclusion}

Salvage rPx after EBRT, BT or HIFU is a feasible and valuable option for a carefully selected individual patient and can lead to a significant BCR-free survival. However, the patient must be well informed about the burden of a salvage procedure. Regarding the poor results of cancer control, we have to realize that failure after EBRT and BT is obviously detected too late and most of the relapse showed a poorly differentiated PC. Therefore, we should consider to escalate the follow up diagnostic, e.g. multiparametric magnetic resonance imaging (mpMRI) or prostate biopsy after 12 months in case of an insufficient PSA level.

\section{Ethical Standards}

All procedures performed in studies involving human participants were in accordance with the ethical standards of the institutional and national research committee and with the 1964 Helsinki declaration and its later amendments or comparable ethical standards.

\section{References}

1. Robert-Koch-Institut (2013) Krebs in Deutschland. Robert-KochInstitut, Berlin, Germany.

2. American Cancer Society (2015) Prostate Cancer Advisory C, Global Cancer Facts \& Figures ( $3^{\text {rd }}$ edn). American Cancer Society, USA.

3. Agarwal PK, Sadetsky N, Konety BR, Resnick MI, Carroll PR (2008) Treatment failure after primary and salvage therapy for prostate cancer: likelihood, patterns of care, and outcomes. Cancer 112(2): 307-314.

4. Grimm P, Billiet I, Bostwick D, Dicker AP, Frank S, et al. (2012) Comparative analysis of prostate-specific antigen free survival outcomes for patients with low, intermediate and high risk prostate cancer treatment by radical therapy. Results from the Prostate Cancer Results Study Group. BJU Int 109(Suppl 1): 22-29.

5. Zagars GK, Pollack A, von Eschenbach AC (1995) Prostate cancer and radiation therapy-the message conveyed by serum prostate-specific antigen. Int J Radiat Oncol Biol Phys 33(1): 23-35.

6. Yock TI, Zietman AL, Shipley WU, Thakral HK, Coen JJ (2002) Longterm durability of PSA failure-free survival after radiotherapy for localized prostate cancer. Int J Radiat Oncol Biol Phys 54(2): 420-426.

7. Gundem G, Van Loo P, Kremeyer B, Alexandrov LB, Tubio JM, et al. (2015) The evolutionary history of lethal metastatic prostate cancer. Nature. 520(7547): 353-357.

8. Stephenson AJ, Eastham JA (2005) Role of salvage radical prostatectomy for recurrent prostate cancer after radiation therapy. J Clin Oncol 23(32): 8198-8203.

9. Grossfeld GD, Stier DM, Flanders SC, Henning JM, Schonfeld W, et al. (1998) use of second treatment following definitive local therapy for prostate cancer: data from the caPSURE database. J Urol 160(4): 13981404.

10. Chade DC, Shariat SF, Cronin AM, Savage CJ, Karnes RJ, et al. (2011) Salvage Radical Prostatectomy for Radiation-recurrent Prostate Cancer: A Multi-institutional Collaboration. Eur Urol 60(2): 205-210.

11. Pisters LL, Leibovici D, Blute M, Zincke H, Sebo TJ, et al. (2009) Locally recurrent prostate cancer after initial radiation therapy: a comparison of salvage radical prostatectomy versus cryotherapy. J Urol 182(2): 517-525.
12. Grossfeld GD, Li YP, Lubeck DP, Broering JM, Mehta SS, et al. (2002) Predictors of secondary cancer treatment in patients receiving local therapy for prostate cancer: data from cancer of the prostate strategic urologic research endeavor. J Urol 168(2): 530-535.

13. Gotto GT, Yunis LH, Vora K, Eastham JA, Scardino PT, et al. (2010) Impact of prior prostate radiation on complications after radical prostatectomy. J Urol 184(1): 136-142.

14. Bianco FJ, Scardino PT, Stephenson AJ, DiBlasio CJ, Fearn PA, et al (2005) Long-term oncologic results of salvage radical prostatectomy for locally recurrent prostate cancer after radiotherapy. Int J Radiat Oncol Biol Phys 62(2): 448-53.

15. Ward JF, Sebo TJ, Blute ML, Zincke H (2005) Salvage surgery for radio recurrent prostate cancer: contemporary outcomes. J Urol 173(4): $1156-1160$

16. Roach M, Hanks G, Thames H, Schellhammer P, Shipley WU, et al. (2006) Defining biochemical failure following radiotherapy with or without hormonal therapy in men with clinically localized prostate cancer: recommendations of the RTOG-ASTRO Phoenix Consensus Conference. Int J Radiat Oncol Biol Phys 65(4): 965-974.

17. Rosen RC, Riley A, Wagner G, Osterloh IH, Kirkpatrick J, et al. (1997) The international index of erectile function (IIEF): a multidimensional scale for assessment of erectile dysfunction. Urology. 49(6): 822-830.

18. Sobin LH, Gospodarowicz MK, Wittekind C (1997) TNM classification of malignant tumors ( $7^{\text {th }}$ edn). John Wiley \& Sons.

19. Tran H, Kwok J, Pickles T, Tyldesley S, Black PC (2014) Underutilization of local salvage therapy after radiation therapy for prostate cancer. Urol oncol 32(5): 701-706.

20. Stephenson AJ, Scardino PT, Bianco FJ, DiBlasio CJ, Fearn PA, et al. (2004) Morbidity and functional outcomes of salvage radical prostatectomy for locally recurrent prostate cancer after radiation therapy. J Urol 172(6 Pt 1): 2239-2243.

21. Vaidya A, Soloway MS (2000) Salvage radical prostatectomy for radiorecurrent prostate cancer: morbidity revisited. J Urol 164(6): 1998-2001.

22. Chen BT, Wood DP (2003) Salvage prostatectomy in patients who have failed radiation therapy or cryotherapy as primary treatment for prostate cancer. Urology 62 (Suppl 1): 69-78.

23. Heidenreich A, Ohlmann C, Ozgur E, Engelmann U (2006) [Functional and oncological outcome of salvage prostatectomy of locally recurrent prostate cancer following radiation therapy]. Der Urologe Ausg A 45(4): 474-481.

24. Heidenreich A, Richter S, Thüer D, Pfister D (2010) Prognostic Parameters, Complications, and Oncologic and Functional Outcome of Salvage Radical Prostatectomy for Locally Recurrent Prostate Cancer after $21^{\text {st }}$ Century Radiotherapy. Eur Urol 57(3): 437-445.

25. Masterson TA, Stephenson AJ, Scardino PT, Eastham JA (2005) Recovery of erectile function after salvage radical prostatectomy for locally recurrent prostate cancer after radiotherapy. Urology 66(3): 623-626.

26. Leonardo C, Simone G, Papalia R, Franco G, Guaglianone S, et al. (2009) Salvage radical prostatectomy for recurrent prostate cancer after radiation therapy. Int J Urol 16(6): 584-586.

27. Kuban DA, Thames HD, Levy LB, Horwitz EM, Kupelian PA, et al. (2003) Long-term multi-institutional analysis of stage T1-T2 prostate cancer treated with radiotherapy in the PSA era. Int J Radiat Oncol Biol Phys 57(4): 915-928.

28. Fuks Z, Leibel SA, Wallner KE, Begg CB, Fair WR, et al. (1991) The effect of local control on metastatic dissemination in carcinoma of the prostate: long-term results in patients treated with $125 \mathrm{I}$ implantation. Int J Radiat Oncol Biol Phys 21(3): 537-547. 
29. Coen JJ, Zietman AL, Thakral H, Shipley WU (2002) Radical radiation for localized prostate cancer: local persistence of disease results in a late wave of metastases. J Clin Oncol 20(15): 3199-3205.

30. Amling CL, Lerner SE, Martin SK, Slezak JM, Blute ML, et al. (1999) Deoxyribonucleic acid ploidy and serum prostate specific antigen predict outcome following salvage prostatectomy for radiation refractory prostate cancer. J Urol 161(3): 857-862.
31. Cheng L, Sebo TJ, Slezak J, Pisansky TM, Bergstralh EJ, et al. (1998) Predictors of survival for prostate carcinoma patients treated with salvage radical prostatectomy after radiation therapy. Cancer 83(10): 2164-2171.

32. Rosoff JS, Savage SJ, Prasad SM (2013) Salvage radical prostatectomy as management of locally recurrent prostate cancer: outcomes and complications. World journal of urology 31(6): 1347-1352.
(C) This work is licensed under Creative Salvage Radical Prostatectomy Compared to Primary Radical Prostatectomy.JOJ uro \& nephron. 2017; 1(3): 555564.

Your next submission with Juniper Publishers
will reach you the below assets
Quality Editorial service
wift Peer Review
eprints availability
-prints Service
Manuscript Podcast for convenient understanding
lobal attainment for your research
Manuscript accessibility in different formats
Pdf, E-pub, Full Text, Audio)
Track the below URL for one-step submission
https://juniperpublishers.com/online-submission.php

